\title{
Recombinational Circularization of Salmonella Phage P22 DNA
}

\author{
STEVEN WEAVER ${ }^{1}$ AND MYRON LEVINE ${ }^{2}$
}

\author{
Department of Human Genetics, The University of Michigan, Ann Arbor, Michigan 48109
}

Accepted August 12, 1976

\begin{abstract}
The development of phage P22 following infection involves a mandatory recombination step, the timing of which is the same in both the lytic and lysogenic pathways. Covalently circular molecules of phage DNA were identified by alkaline sucrose sedimentation of infected cell lysates. The time of appearance of these structures corresponds to the time of the essential recombination step. On infection of $\mathrm{rec}^{-}$cells, the action of the P22 recombination function, erf, is necessary for the formation of covalent circles. The amount of covalently circular parental phage DNA observed in lytically infected cells is lower than are the levels found in cells destined for lysogeny. Evidence is presented that the lower levels in the former case are due to the conversion of covalently circular molecules to some other structure by a replicational process.
\end{abstract}

\section{INTRODUCTION}

The development of phage P22 after infection, in both the lytic and lysogenic modes, requires recombination. This requirement can be satisfied by either of the two available recombination systems: that of the host bacterium, rec, or that coded by the phage itself, erf (Botstein and Matz, 1970; Yamagami and Yamamoto, 1970). During both the lytic and lysogenic responses, the essential recombinational event takes place at the same time (Weaver and Levine, 1976), suggesting that the process may be the same in both cases. Following induction, however, the production of progeny phage does not require the action of either erf or rec (Botstein and Matz, 1970). Since the excision of P22 prophage presumably results in a circular molecule (Campbell, 1962), Botstein and Matz surmised that the requirement for recombination following infection reflected the need for the parental DNA to be circularized. The DNA molecules carried by P22 particles are linear duplexes possessing terminally redundant ends

${ }^{1}$ Present address: Department of Bacteriology and Immunology, The University of North Carolina, Chapel Hill, North Carolina 27514.

${ }^{2}$ Author to whom reprint requests should be addressed.
(Rhoades et al., 1968). Circularization of such molecules could be accompolished by recombination at the terminal redundancies. The Campbell model (1962) for integration predicts that circular phage DNA would be a required intermediate in the establishment of lysogeny. Parental P22 DNA has been observed in the form of covalently closed circles during infections leading to lysogeny (Rhoades and Thomas, 1968). During the lytic response, circularization might be required for the formation of an essential replicating structure, such as a "rolling circle" (Gilbert and Dressler, 1968).

In this communication, we present experiments which test the hypothesis that the circularization of parental phage DNA following infection is the essential recombination event.

\section{MATERIALS AND METHODS}

Bacteria and phage. All bacterial strains used are derivatives of Salmonella typhimurium LT-2. Strain 18 (wild type) and strain $330\left(\mathrm{rec}^{-}\right)$have been described (Weaver and Levine, 1976). Strain 202 is a thymidine-requiring derivative of strain 18. Wild-type P22 $c^{+}$, the clear mutant $c 2$ 5 , and the erf mutation $t s 65$ have been described (Weaver and Levine, 1976). The gene 12 mutation am $\mathrm{H} 80$ was described by 
Bode et al. (1973). Recombinant phage were constructed by standard techniques.

Media and buffers. M9CAA (Smith and Levine, 1964) and LCG20 (Botstein, 1968) have described. TESA is $10 \mathrm{mM}$ Tris-Cl, pH 8.0, $10 \mathrm{~m} M$ EDTA, $50 \mathrm{mM} \mathrm{NaCl}$. TESB is $10 \mathrm{~m} M$ Tris-Cl, pH 8.1, $1 \mathrm{mM}$ EDTA, 10 $\mathrm{m} M \mathrm{NaCl}$. SSC is $0.15 \mathrm{M} \mathrm{NaCl}, 0.015 \mathrm{M}$ Na-citrate, $\mathrm{pH} 8.0$.

Radioactive phage and phage DNA. Phage labeled with ${ }^{32} \mathrm{P}$ were produced by the method of Botstein (1968). Tritiumlabeled phage were obtained by infecting strain 202, which was grown in M9CAA supplemented with $5 \mu \mathrm{g} / \mathrm{ml}$ of thymidine. At the time of infection, $\left[{ }^{3} \mathrm{H}\right]$ thymidine (20-50 $\mathrm{Ci} / \mathrm{mmole})$ was added to give $5-20$ $\mu \mathrm{Ci} / \mathrm{ml}$.

Phage were concentrated by differential centrifugation, incubated with excess purified base-plate protein (Weaver and Levine, 1976), and sedimented through a discontinuous $\mathrm{CsCl}$ density gradient as described by Botstein (1968).

DNA was purified from phage particles by three extractions with TESB-saturated, redistilled phenol at room temperature, followed by dialysis in the cold versus TESB. The dialysis tubing was boiled beforehand in sodium bicarbonate as described by Rhoades et al. (1968).

Preparation of cell lysates. Unless otherwise noted, bacteria were grown to a concentration of $1 \times 10^{8} / \mathrm{ml}$ in M9CAA and infected at a multiplicity of infection (m.o.i.) of $10 \mathrm{PFU} /$ cell.

Lysis method A: The culture to be lysed, 5 to $10 \mathrm{ml}$, was transferred to a centrifuge tube containing $10 \mu \mathrm{l}$ of $1 M \mathrm{NaCN}_{3}$. The cells were pelleted in the cold, resuspended in the original volume SSC, repelleted, and resuspended once again at three times the original cell concentration in SSC. One-tenth volume of a $5 \%$ solution of sodium dodecyl sulfate (SDS) was added, and the mixture was incubated for $15 \mathrm{~min}$ at $37^{\circ}$. One-tenth volume of a $10-\mathrm{mg} / \mathrm{ml}$ solution of Pronase (Calbiochem, "nuclease-free") was added, and the incubation was continued for 4 to $6 \mathrm{hr}$.

Lysis method B: The culture was mixed with $1 / 10$ vol of $1.5 M \mathrm{NaCl}, 0.15 \mathrm{M} \mathrm{Na}$ citrate, $\mathrm{pH}$ 8.0, $0.1 \mathrm{M} \mathrm{NaCN}_{3}$. One-tenth volume of $10 \%$ SDS was added, and the mixture was incubated for $15 \mathrm{~min}$ at $37^{\circ}$. Pronase digestion was carried out as in Method A.

Phenol extractions were performed by mixing the lysate with an equal volume of redistilled phenol, saturated with dialysis buffer (TESA or TESB). An emulsion was formed by inverting the tube gently about once per second for $5 \mathrm{~min}$. Dialysis was carried out in tubing boiled as described above, against three or four 1-liter changes of buffer.

Sucrose gradient analyses. Gradients were built in $5-\mathrm{ml}$ polyallomer tubes by carefully overlaying $0.9-\mathrm{ml}$ volumes of 20 , $16.75,12.5,8.25$, and $5 \%$ sucrose solution, using a sterile long-tip pipet. Solutions of neutral sucrose contained $10 \mathrm{~m} M$ Tris- $\mathrm{Cl}$, pH 7.4, $0.5 \mathrm{~m} M$ EDTA, $0.1 M \mathrm{NaCl}$. Alkaline sucrose solutions contained $0.15 \mathrm{M}$ $\mathrm{NaOH}, 0.85 \mathrm{M} \mathrm{NaCl}$. If the lysate to be analyzed contained detergent, gradients were constructed from solutions supplemented with $0.1 \%$ sodium dodecyl sarcosinate. All solutions were sterilized by filtration and kept sterile. The discontinuous gradients were allowed to diffuse to linearity overnight at room temperature. Just before use, $0.3 \mathrm{ml}$ of a solution containing 20\% sodium iothalmate (Angio-Conray) and $80 \%$ sucrose (Botstein, 1968) was injected underneath the gradients by means of a syringe and cannula. This provided a dense cushion under the gradients, allowing the recovery of fast-sedimenting material. The volume of lysate analyzed on each gradient was $0.1-0.2 \mathrm{ml}$. Lysates to be centrifuged through alkaline gradients were denatured by the addition of $1 / 5 \mathrm{vol}$ of $1 M \mathrm{NaOH}$ before layering.

Gradients were centrifuged in a Beckman SW50.1 rotor at $20^{\circ}$ and collected by puncturing the bottom of the tube with a cannula. In some cases, fractions were collected onto paper strips, which were dried and counted in a toluene-based scintillation fluid (Smith, 1968). Alternatively, fractions were collected into tubes, 2 drops of carrier DNA (salmon sperm DNA; $1 \mathrm{mg}$ / $\mathrm{ml}$ in TESB) were added, and the mixture was precipitated by the addition of $1 \mathrm{ml}$ of cold $10 \%$ trichloroacetic acid. The precipi- 
tates were collected on Whatman GF/C glass fiber filters, rinsed with cold ethanol, dried, and counted as above.

\section{RESULTS}

Rhoades and Thomas (1968) observed covalently circular molecules of parental DNA in P22-infected cells destined for lysogeny. In the following experiment, we repeated their procedure and obtained similar results. A culture of strain 18 cells growing at $37^{\circ}$ was infected with ${ }^{32} \mathrm{P}$-labeled $c^{+}$phage; the multiplicity of infection, 10 per cell, was sufficient to cause the lysogenic response in at least $90 \%$ of the infected cells. Thirty minutes later, the culture was lysed by method $A$, which is identical with the procedure employed by Rhoades and Thomas (1968), extracted with phenol and dialyzed versus TESA. On sedimentation through a neutral sucrose gradient, the labeled species of DNA in the lysate were resolved into two peaks (Fig. 1A), one of which was centered in fraction 35 , while a second, moving 1.7 times faster than the first, was found in fraction 17. Our gradients included a dense pad at the bottom to allow the recovery of very rapidly sedimenting material that otherwise would pellet and be unrecoverable. A substantial fraction of the total radioactivity comes to rest on the cushion as a third "peak" in fraction 6. Little can be said on the basis of our data about the nature of this material. Possibly, it is associated with some rapidly sedimenting cellular component (Botstein, 1968).

On sedimentation of their lysates through gradients identical to those used here, Rhoades and Thomas (1968) also observed two peaks, one sedimenting at $35 \mathrm{~S}$, and one sedimenting 1.7 times faster, at 60 $\mathrm{S}$. They showed that the $35 \mathrm{~S}$ zone contained molecules indistinguishable from those contained in mature P22 particles. The material in the $60 \mathrm{~S}$ band exhibited the properties expected for covalently circular molecules of the same molecular weight as mature P22 DNA. It was resistant to mechanical shearing, and following denaturation it could spontaneously renature. The latter property was used to purify the putative covalent circles from

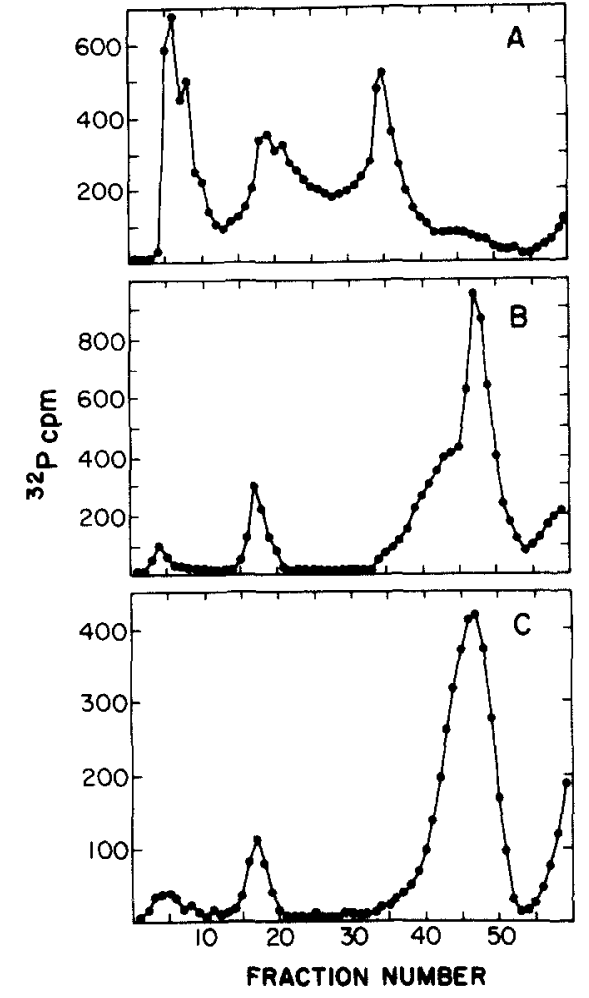

FIG. 1. Appearance of parental phage DNA as covalently closed circles in infections leading to lysogeny. Sucrose gradient analyses were performed as described in Materials and Methods. All centrifugations were carried out at $45,000 \mathrm{rpm}$. (A) Neutral sucrose analysis of the phenol-extracted lysate; 75 min spin. (B) Alkaline sucrose analysis of the phenol-extracted lysate; centrifugation was for 35 min. (C) Analysis of the unextracted lysate in alkaline sucrose. Before layering, the viscous lysate was placed in a $12 \times 75-\mathrm{mm}$ tube and sheared at top speed on a vortex mixer. Centrifugation was for 35 min. Fractions from all three gradients were collected on paper strips. In this and subsequent figures, sedimentation is from right to left.

other species in the lysate by hydroxyapatite chromatography after denaturation and renaturation. Examination of this material in the electron microscope revealed circular supercoiled molecules.

That our lysates contained the two components observed and characterized by Rhoades and Thomas (1968) was confirmed by sedimentation through an alkaline sucrose gradient (Fig. 1B). The major DNA species banded in fraction 47 ; this peak possessed a pronounced leading shoulder. 
A second, smaller band of radioactivity was located at fraction 17 ; this material sedimented 3.5 times faster than the major species. Rhoades and Thomas (1968) showed that the two zones seen in the alkaline gradient contained DNA species that corresponded to the two bands found in neutral gradients. On denaturation, covalently closed circular molecules (the $60 \mathrm{~S}$ zone in neutral gradients) assume a collapsed configuration and sediment in alkaline gradients (containing $0.85 \mathrm{M} \mathrm{NaCl}$ ) 3.5 times more rapidly than singlestranded linear molecules derived from monomeric linear duplexes (the $35 \mathrm{~S}$ zone in neutral gradients).

The material in the peak of putative covalent circles at fraction 17 of Fig. 1B included about $10 \%$ of the total radioactivity on the gradient, a value very similar to that reported for alkaline sucrose analyses by Rhoades and Thomas (1968). To investigate whether this material had been selectively lost or destroyed during the phenol extraction step, a portion of the original lysate (which had been neither extracted with phenol nor dialyzed) was analyzed in alkaline sucrose (Fig. 1C). In the position expected for covalently circular molecules, a peak containing about $10 \%$ of the total radioactivity was found. Thus, these structures are apparently not preferentially lost or destroyed during phenol extraction.

We have found that neutral sucrose gradient analysis of our lysates is not a reliable method for the identification of covalently circular molecules. In neutral gradients neither the shape of the zone of "covalent circles" at the $60 \mathrm{~S}$ position nor the amount of material in this zone was particularly reproducible. In contrast, the size and shape of the covalent circles peak in alkaline sucrose gradient profiles was quite reproducible. Some of the difficulty with neutral sucrose gradients appears to be related to the fact that the bulk of the bacterial DNA in our lysates sediments as a poorly defined zone from $50-70 \mathrm{~S}$ (data not shown).

In the balance of the experiments reported here, the amount of covalently circular phage DNA was measured by alkaline sucrose sedimentation analysis. As an operational definition, any material sedimenting 3.5 times faster than a marker of single-stranded monomeric DNA was assumed to consist of denatured covalently circular duplexes of monomer molecular weight. Although we believe this to be a reliable criterion, we have not confirmed the structure of our "covalent circles" by independent means.

\section{Circularization of Parental DNA in Lytic Infections}

Tritium-labeled $c 2-5$ phage were used to infect strain 18 cells at $25^{\circ}$. The $c 2-5$ mutation ensures entry into the lytic pathway. The infection was performed at $25^{\circ}$ so that the results could be correlated with the results of temperature-shift experiments (Weaver and Levine, 1976; and the following section). At intervals after infection, portions of the culture were lysed by Method A and dialyzed, without phenol extraction, against TESA in the cold. Each preparation was analyzed by alkaline sucrose sedimentation in the presence of a ${ }^{32} \mathrm{P}$-labeled mature phage DNA marker (Fig. 2). Covalently circular DNA was first detected in the lysate prepared $20 \mathrm{~min}$ after infection; subsequent lysates contained circular DNA in increasing amounts. Figure 3 summarizes the information of Fig. 2: Here the amount of phage DNA in covalent circles is expressed as a percentage of the total ${ }^{3} \mathrm{H}$ label and is plotted versus time after infection. Circular forms accumulate from 20 to $40 \mathrm{~min}$; from $40 \mathrm{~min}$ on, the proportion remains constant at about $1 \%$.

The results of genetic experiments (Weaver and Levine, 1976) indicated that the recombinational events which are necessary for normal P22 lytic growth occur between the 20th and 30th min after infection at $25^{\circ}$. That finding and the present observation that circles begin to accumulate at $20 \mathrm{~min}$ are consistent with the notion of Botstein and Matz (1970) that the essential event is recombinational circularization of the terminally redundant parental DNA molecule. The significance of the very low levels of covalent circles will be considered below. 


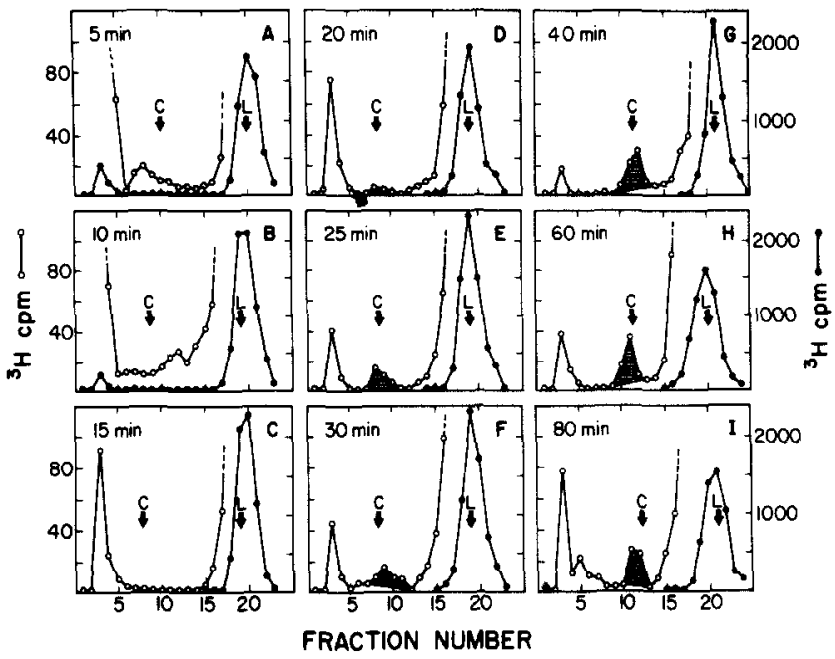

Fig. 2. Appearance of ${ }^{3} \mathrm{H}$-labeled parental phage DNA as covalently closed circles during lytic infection. Each lysate was analyzed by alkaline sucrose sedimentation for $30 \mathrm{~min}$ at 45,000 rpm. A small amount of purified ${ }^{32}$ P-labeled P22 DNA was included as sedimentation marker. Fractions were precipitated with trichloroacetic acid and collected on filters. The open circles show the distribution of ${ }^{3} \mathrm{H}$ label in the lower portion of each gradient on an expanded scale. The arrows indicate the position of the peak of marker DNA (L) and the position expected for covalently closed circles (C), which should sediment 3.5 times faster than the linear marker in gradients of this composition. The amount of circular DNA was estimated as indicated by the shaded portion of each profile.

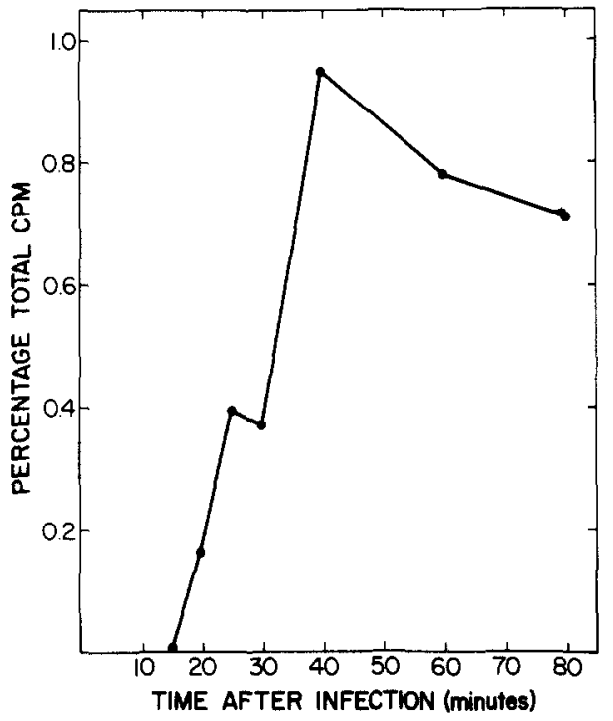

Fig. 3. Time course of accumulation of parental phage DNA as covalent circles in lytic infections. For Figs. 2C-2I the proportion of the total ${ }^{3} \mathrm{H}$ radioactivity in each gradient that sedimented as covalent circles (that lying within the shaded area) was calculated. The values, expressed as percentages, are plotted against time after infection. No points are included from Figs. $2 \mathrm{~A}$ and $2 \mathrm{~B}$. Since there are clearly no covalent circles in the 15-min lysate (Fig. 2C), one may assume that none were present at earlier times.

\section{Temperature-Shift Experiments}

In the accompanying paper (Weaver and Levine, 1977), the timing of the required recombination step was deduced by observing the effects of temperature shift upon lytic growth and on lysogenization by erf-ts phage in $\mathrm{rec}^{-}$hosts. Here we present a similar analysis to demonstrate that erf is required for circularization of parental phage DNA in infections of rec- cells and to show the kinetics of the requirement for recombination. An infection of strain 330 cells by ${ }^{32} \mathrm{P}$-labeled erf-ts $65 c 2-5$ phage was initiated at $25^{\circ}$. Beginning at $10 \mathrm{~min}$ after infection, and at 5-min intervals thereafter, portions of the infected culture were transferred to $39^{\circ}$, a temperature nonpermissive for the erf-ts 65 allele. At $35 \mathrm{~min}$, a portion of each of the shifted cultures, as well as a portion of the unshifted control, was lysed by Method A; the lysates were neither extracted nor dialyzed. At the end of the latent period, the burst size of each of the cultures was determined.

Alkaline sucrose sedimentation analysis was carried out to observe the effect of temperature shift on the extent of circularization of parental phage DNA. The lower 
half of each of the gradients is presented in Fig. 4. No covalent circles were obtained from cultures shifted up at 10 or $15 \mathrm{~min}$. Shifting up at 20 min allowed the formation of a few covalent circles; delaying the time of shift to 25 or $30 \mathrm{~min}$ allowed the parental DNA to be circularized to an increasing extent. The results of Fig. 4 are summarized in Fig. 5. Here the percentage of parental radioactivity sedimenting as covalent circles is plotted versus the time of temperature shift. The effect of temperature shift on burst size is also shown. It is clear that temperature shifts before $20 \mathrm{~min}$ inhibit both replication and the formation of covalently circular parental DNA. Delaying the temperature shift from 20 to 30 min allows a steady increase in the extent of circularization and a concomitant in-

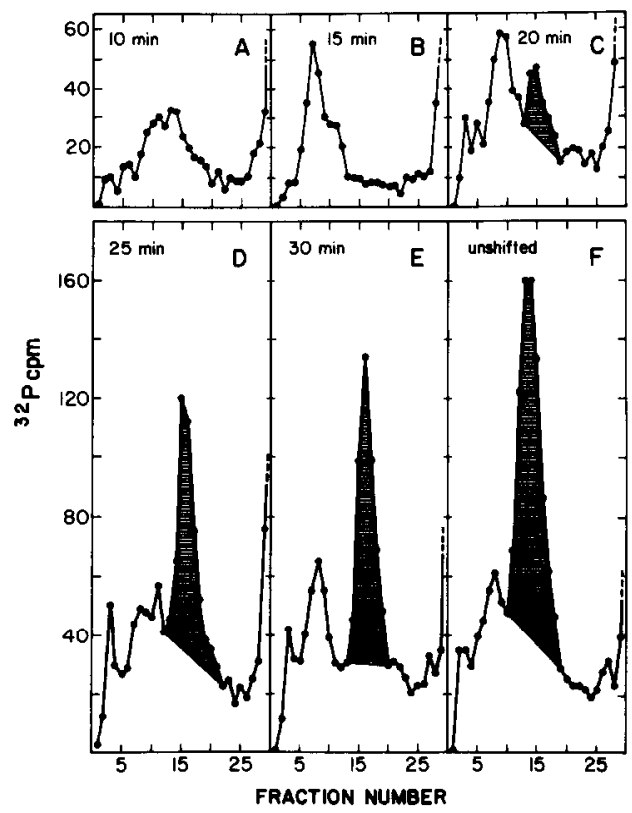

Fig. 4. Effect of shift to nonpermissive temperature on the circularization of parental phage DNA in $\mathrm{rec}^{-}$cells infected with ${ }^{32} \mathrm{P}$-labeled erf-ts65 c2-5 phage. Lysates were analyzed on alkaline sucrose gradients; a marker of ${ }^{3} \mathrm{H}$-labeled phage DNA was included. Centrifugations were for $35 \mathrm{~min}$ at 45,000 rpm. Fractions were collected on paper strips. Only the first 30 of the approximately 50 fractions obtained from each gradient are shown. The infected cultures were transferred from 25 to $39^{\circ}$ at the indicated times, and then lysed at 35 min after infection. The shaded areas indicate the region under the curve assumed to be covalent circles.

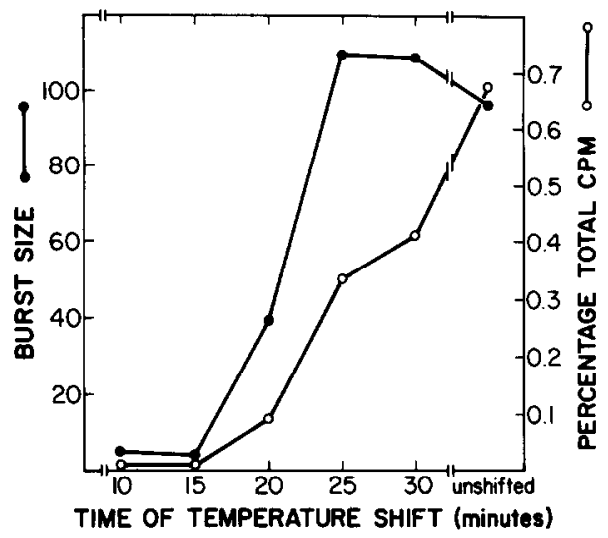

Fig. 5. Comparison of the effects of temperature shift on burst size and on circularization of erf-ts $c 2$ phage DNA on infection of $\mathrm{rec}^{-}$cells. For each profile of Fig. 4, the percentage of total DNA coverted to covalently closed circles (shaded peaks in Fig. 4) by 35 min after infection is shown ( $\mathrm{O}-\mathrm{O}$ ). The burst size, expressed as progeny per infected cell, for each of the corresponding cultures is also plotted (O-O).

crease in burst size. Thus, the action of erf during the 20 - to 30 -min interval at $25^{\circ}$ is required for the circularization of parental DNA and is also required for lytic replication. This correlation provides additional support for the hypothesis (Botstein and Matz, 1970) that circularization is the event for which recombination is required.

\section{Appearance of Newly Synthesized DNA in Covalent Circles}

A culture of strain 202 cells was infected with $c 2-5$ phage at $25^{\circ}$. Simultaneously, $\left[{ }^{3} \mathrm{H}\right]$ thymidine $(40 \mu \mathrm{Ci} / \mathrm{ml} ; 50 \mathrm{Ci} / \mathrm{mmole})$ was added. At intervals, aliquots of the culture were lysed by Method B, dialyzed against TESA at room temperature, and analyzed on alkaline sucrose gradients. The percentages of total acid-insoluble ${ }^{3} \mathrm{H}$ sedimenting as covalently circular DNA are given in Table 1. Circular molecules began to accumulate $20 \mathrm{~min}$ after infection. However, they are no more abundant than circularized molecules containing parental phage DNA (Fig. 3).

\section{Circularization of Parental DNA when Phage DNA Synthesis Is Inhibited}

The results presented thus far indicate that covalently circular phage DNA is 
TABLE 1

The Appearance of Newly Synthesized P22 DNA as Covalently Closed Circles ${ }^{a}$

\begin{tabular}{cc}
$\begin{array}{c}\text { Time after infection } \\
\text { (min) }\end{array}$ & $\begin{array}{c}\text { Percentage covalent cir- } \\
\text { cles }\end{array}$ \\
\hline 1 & $-{ }^{b}$ \\
11 & $--^{b}$ \\
21 & 0.18 \\
31 & 0.37 \\
41 & 0.29 \\
51 & 1.17
\end{tabular}

${ }^{a}$ The data were obtained from alkaline sucrose gradient profiles by criteria similar to those illustrated in Fig. 2. Gradients were run 3 days after the lysates were prepared. Fractions were precipitated and collected on filters.

${ }^{b}$ None detected.

present in lytically infected cells in levels lower than those seen in cells destined for lysogeny (Figs. 1 and 3). A similar observation has been reported by Thomas $e t$ al. (1968). These low levels require explanation, in view of the fact that circularization of parental DNA is thought to be prerequisite to lytic replication. It is difficult to envision a way to produce a concatemer from a covalently circular duplex template that would not involve the destruction of its covalent integrity. It seemed reasonable that circularized parental DNA would be a transient intermediate in the lytic case and that although a large proportion of the total parental molecules might undergo circularization, only a small fraction could be isolated in that state at any given time.

We tested this notion by measuring the accumulation of circular parental DNA under conditions in which phage DNA synthesis was blocked by a mutation in gene 12 (Levine and Schott, 1971). Strain 18 cells $\left(s u^{-}\right)$were infected with ${ }^{32} \mathrm{P}$-labeled $c 2-512$-am $\mathrm{H} 80$ phage at $25^{\circ}$. At intervals, portions of the culture were lysed and analyzed by alkaline sucrose sedimentation. In this experiment, lysis method B was employed; the lysates were neither extracted nor dialyzed before analysis. The extent of conversion of parental DNA to the covalently circular configuration is presented in Table 2. Covalently circular molecules were first observed at $20 \mathrm{~min}$ after infection; by $40 \mathrm{~min}$, almost $4 \%$ of the total parental label was found in this form. This level is roughly fourfold greater than those levels observed in previous experiments, in which at most $1 \%$ of the parental DNA was recoverable as covalent circles by $40 \mathrm{~min}$. This finding suggests that the very low levels of covalently circular parental DNA in lytic infections may be in part a consequence of the disruption of the integrity of these molecules by the onset of replication. The fact that lysis method $B$, rather than method $A$, was used in this experiment is probably not a factor in the increased levels of covalent circles, since the differences between the two methods are minor. Further, we have found that method $B$ gives the characteristic low levels of circularization (1\% or less) of parental DNA in $c 2.512^{+}$infections (data not shown).

The nature of the replicational defect associated with gene 12 mutations is not known. Although no phage DNA is synthesized (Levine and Schott, 1971; Bode et $a l ., 1973)$, it is possible that replicationassociated nicking of covalently circular molecules might still occur despite the block associated with the $12^{-}$mutation. If such nicking did occur, one might then expect relaxed (covalently open) circles to accumulate, particularly when replication is inhibited. Another general explanation for the low levels of covalently circular molecules during the lytic response is that

TABLE 2

The Appearance of Covalently Closed Circles in the Absence of DNA Replication ${ }^{a}$

\begin{tabular}{cc}
\hline $\begin{array}{c}\text { Time after infection } \\
(\mathrm{min})\end{array}$ & $\begin{array}{c}\text { Percentage covalent cir- } \\
\text { cles }\end{array}$ \\
\hline 2 & $-{ }^{b}$ \\
6 & $-{ }^{b}$ \\
10 & $-{ }^{b}$ \\
20 & 0.07 \\
30 & 1.2 \\
40 & 3.8 \\
\hline
\end{tabular}

a These data were obtained as described in the text and in the legend to Table 1 . Gradients were run 1 day after the preparation of the lysates. Fractions were collected on paper strips. The gradient from which the 40 -min result was obtained is shown in Fig. 6A.

- None obtained. 
they are not the important circular form at all; rather, relaxed circles could be the immediate product of the essential recombination event. This notion also leads to the prediction that relaxed circles might accumulate in gene 12 mutant infections. To investigate this possibility, the lysate prepared $40 \mathrm{~min}$ after infection (see Table 2 , line 6; the alkaline sucrose gradient of Fig. 6A shows the peak of covalent circles in this lysate) was reanalyzed in both neutral (Fig. 6B) and alkaline (Fig. 6C) sucrose gradients. To resolve relaxed circular duplexes and single-stranded circular molecules from linear monomers, it is necessary to sediment these species nearly to
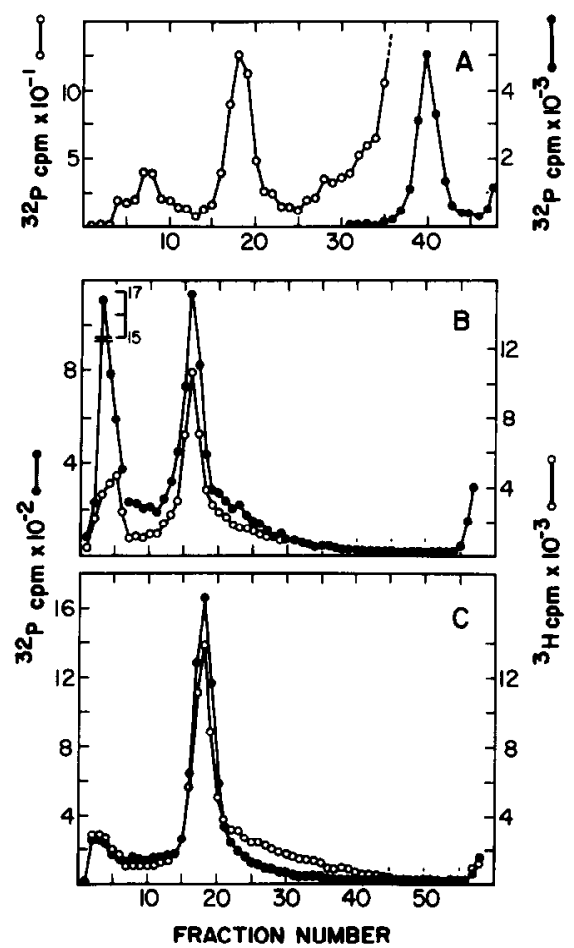

Fig. 6. Fate of parental phage DNA when replication is blocked. A lysate prepared $40 \mathrm{~min}$ after infection of strain 18 cells with ${ }^{32}$ P-labeled c2-5 12am $\mathrm{H} 80$ phage was centrifuged for (A) $30 \mathrm{~min}$ in an alkaline gradient, (B) $120 \mathrm{~min}$ in a neutral gradient, and (C) $120 \mathrm{~min}$ in an alkaline gradient. In the gradient of $\mathbf{A}$, the marker (not shown) sedimented with the major band of ${ }^{32} \mathrm{P}$ in fraction 40 . The distribution of ${ }^{32} \mathrm{P}$ in the lower portion of $\mathrm{A}(\mathrm{O}-\mathrm{O})$ is plotted on a scale different from that used in the upper portion of this panel (- Fractions from these gradients were collected on paper strips. the bottom of a gradient. Relaxed circles, which sediment 1.14 times faster than linear molecules (Rhoades and Thomas, 1968), in our gradients would be expected to band in fraction 10 in Fig. 6B. Similarly, in the alkaline gradient of Fig. 6C, singlestranded circles, sedimenting 1.13 times faster than single-stranded linear molecules (Rhoades and Thomas, 1968), would be found in fraction 13. (Covalent circles would be found on the cushion in both gradients.) In neither gradient is there any evidence for such structures. However, in the neutral gradient (Fig. 6B), a substantial proportion of parental label was found on the cushion (fraction 3). We cannot exclude the possibility that some relaxed circles, perhaps associated with a fast sedimenting replication complex (Botstein, 1968) were present in this "cushion" material. In the alkaline gradient, rapidly sedimenting aggregates are not a problem. In Fig. 6C, the sedimentation pattern of parental DNA is indistinguishable from that of the marker. Thus, although at least $4 \%$ of the parental molecules appeared as covalent circles by $40 \mathrm{~min}$ after infection (Table 2, line 6; Fig. 6A), the bulk of the parental molecules seems to undergo no detectable modification. In particular, none seem to be converted to a form that would yield a single-stranded circular molecule on denaturation.

Attempts to demonstrate relaxed circular molecules when DNA synthesis was not inhibited were also unsuccessful (data not shown). P22 replication produces large amounts of concatemeric DNA which contains parental label (Botstein, 1968; Botstein and Levine, 1968). This material sediments at the same rate as that expected for single-stranded circles in alkaline gradients.

\section{DISCUSSION}

Our knowledge of the occurrence of circular phage DNA in P22 infections may be summarized as follows. In lytic development at $25^{\circ}$, covalently circular molecules of parental DNA begin accumulating after $20 \mathrm{~min}$. In infections leading to lysogeny performed at $37^{\circ}$, covalent circles first appear at about the 10th min (Rhoades and 
Thomas, 1968). Although it has not been shown directly, we presume that covalently circular parental DNA would appear at $10 \mathrm{~min}$ in lytic infections at $37^{\circ}$, and after $20 \mathrm{~min}$ in lysogenizing infections at $25^{\circ}$. The appearance of circular molecules correlates with the timing of the essential recombination step, as deduced from genetic experiments (Weaver and Levine, 1976).

Temperature-shift experiments demonstrate more directly the temporal relationship between circularization and the essential step. When a culture of $\mathrm{rec}^{-}$cells lytically infected with erf-ts phage is transferred from permissive to nonpermissive temperature before the 20 th $\mathrm{min}$, the essential recombination event is prevented, the infection is essentially nonproductive, and no covalently circular molecules of parental DNA are produced. When the temperature shift is delayed beyond the 20th min, a situation increasingly permissive for replication is established and covalently circular parental DNA accumulates. This evidence strongly suggests that erf function is responsible for the circularization of linear parental DNA in lytic growth, presumably by promoting recombination between the terminally repetitious ends. It should be pointed out that our data do not prove that the inability to circularize the parental chromosome is the basis for the failure of erf phage to replicate in or to lysogenize $\mathrm{rec}^{-}$hosts; in other words, whether circularization is, in fact, an essential event. Although covalent circles are clearly produced, other recombinational events could a priori be imag. ined to be essential.

In infections leading to lysogeny, as much as $10 \%$ of the total parental DNA is converted to covalent circles. However, in lytic infections in which replication is allowed to proceed, no more than about $1 \%$ of the total parental label has been observed in the covalently circular form. This result does not rule out the possibility that circular molecules are important for lytic replication. Several arguments suggesting that the low levels are misleading may be proposed: A need for circularization does not necessarily imply that the immediate product of the essential recombination event would be a covalently circular duplex; the important structure could just as well be a relaxed circular molecule containing nicks in either or both of its strands. Another possibility is that covalently circular molecules are indeed the product of the essential recombination event, but that they are transient intermediates in replication. Support for this notion is provided by our observation that covalent circles accumulate in significantly higher amount in lytically infected cells when phage replication is blocked. The problem of degradation of labeled covalent circles in our lysates is substantial. We estimate that under the most unfavorable combination of circumstances, covalent circles would have had a half-life of about 2 days. Since all sedimentation analyses were performed within 2 or 3 days of the preparation of lysates, degradation can at most account for about a twofold underestimate of the intracellular levels of covalently circular DNA. It should be emphasized that we have no way to estimate the extent of any destruction of circles that takes place during the lysis manipulations themselves.

Our experiments consisted of measuring the percentage of total label found in the form of covalent circles. A difficulty in interpreting the results of this kind of analysis is the uncertainty about how much of the parental DNA is actually participating in the infection. Botstein and Levine (1968) found that only 25 to $30 \%$ of the parental DNA enters the replication complex. These considerations suggest that the amount of covalent circles that we observed may underestimate by as much as a factor of 3 the extent to which effectively infectious parental DNA is circularized.

\section{REFERENCES}

Bode, W., Dopatka, H. D., and Prell, H. H. (1973). Functional classification of P22 amber mutants. Mol. Gen. Genet. 127, 341-347.

Botstein, D. (1968). Synthesis and maturation of phage P22 DNA: I. Identification of intermediates. J. Mol. Biol. 34, 621-641.

Botstein, D., and Levine, M. (1968). Synthesis and maturation of phage P22 DNA: II. Properties of temperature-sensitive phage mutants defective in 
DNA metabolism. J. Mol. Biol. 34, 643-654.

Botstrin, D., and MATz, M. J. (1970). A recombination function essential to the growth of bacteriophage P22. J. Mol. Biol. 54, 417-440.

CAMpbell, A. (1962). Episomes. Advan. Genet. 11, 101-145.

Gilbert, W., and Dressler, D. (1968). DNA replication: The rolling circle model. Cold Spring Harbor Symp. Quant. Biol. 33, 473-484.

Levine, M., and Schotт, C. (1971). Mutations of phage P22 affecting phage DNA synthesis and lysogenization. J. Mol. Biol. 62, 53-64.

Rhoades, M., Machattie, L. A., and Thomas, C. A., JR. (1968). The P22 bacteriophage DNA molecules: I. The mature form. J. Mol. Biol. 37, 21-40.

Rhoades, M., and Thomas, C. A. (1968). The P22 bacteriophage DNA molecule: II. Circular intracellular forms. J. Mol. Biol. 37, 41-61.

Sмттн, H. O. (1968). Defective phage formation by lysogens of integration deficient phage P22 mutants. Virology 34, 203-223.

Smith, H. O., and Levine, M. (1964). Two sequential repressions of DNA synthesis in the establishment of lysogeny by phage P22 and its mutants. Proc. Nat. Acad. Sci. USA 52, 356-363.

Thomas, C. A., Kelley, T. J., JR., and Rhoades, M. (1968). The intracellular forms of T7 and P22 DNA molecules. Cold Spring Harbor Symp. Quant. Biol. 33, 417-424.

WEAVER, S., and LeVINe, M. (1977). The timing of erf-mediated recombination in replication, lysogenization, and the formation of recombinant progeny by Salmonella phage P22. Virology, 76, 19-28.

Yamagami, H., and Yamamoto, N. (1970). Contribution of the bacterial recombination function to replication of bacteriophage P22. J. Mol. Biol. 53, 281-285. 